\title{
Sonic Hedgehog Signaling and Development of the Dentition
}

\author{
Maisa Seppala ${ }^{1,2}$, Gareth J. Fraser ${ }^{3}$, Anahid A. Birjandi ${ }^{1}$, Guilherme M. Xavier ${ }^{1,2}$ and \\ Martyn T. Cobourne 1,2,* \\ 1 Centre for Craniofacial and Regenerative Biology, King's College London Dental Institute, Floor 27, \\ Guy's Hospital, London SE1 9RT, UK; maisa.seppala@kcl.ac.uk (M.S.); \\ anahid.ahmadi_birjandi@kcl.ac.uk (A.A.B.); guivier@hotmail.com (G.M.X.) \\ 2 Department of Orthodontics, King's College London Dental Institute, Floor 22, Guy's and St Thomas' NHS \\ Foundation Trust, London SE1 9RT, UK \\ 3 Department of Animal and Plant Sciences, Alfred Denny Building, University of Sheffield, \\ Sheffield S10 2TN, UK; g.fraser@sheffield.ac.uk \\ * Correspondence: martyn.cobourne@kcl.ac.uk; Tel.: +44-207-188-8028; Fax: +44-207-188-1674
}

Academic Editors: Henk Roelink and Simon J. Conway

Received: 4 May 2017; Accepted: 28 May 2017; Published: 31 May 2017

\begin{abstract}
Sonic hedgehog (Shh) is an essential signaling peptide required for normal embryonic development. It represents a highly-conserved marker of odontogenesis amongst the toothed vertebrates. Signal transduction is involved in early specification of the tooth-forming epithelium in the oral cavity, and, ultimately, in defining tooth number within the established dentition. Shh also promotes the morphogenetic movement of epithelial cells in the early tooth bud, and influences cell cycle regulation, morphogenesis, and differentiation in the tooth germ. More recently, Shh has been identified as a stem cell regulator in the continuously erupting incisors of mice. Here, we review contemporary data relating to the role of Shh in odontogenesis, focusing on tooth development in mammals and cartilaginous fishes. We also describe the multiple actions of this signaling protein at the cellular level.
\end{abstract}

Keywords: odontogenesis; initiation; patterning; dental mesenchymal stem cells; tooth number

\section{Introduction}

Sonic hedgehog (Shh) signaling plays a key role in multiple developmental processes in vertebrates [1-3]. Shh is a highly-conserved marker for tooth development amongst all the toothed vertebrates [4-9]. The mammalian tooth is a site of dynamic Shh signaling activity, which begins in the dental lamina during initiation, and continues in well-defined regions of the tooth germ epithelium during subsequent coronal and root morphogenesis [8-13]. Several early investigations highlighted the importance of Shh signal transduction during mammalian tooth development, which includes the specification of boundaries between odontogenic and non-odontogenic epithelium during initiation, as well as cell cycle regulation, differentiation, and morphogenesis in the established tooth germ [9,14-17]. More recently, studies have identified a role for Shh in promoting morphogenetic movement in the early tooth bud through cell polarization, influencing both cuspal morphogenesis and root development during the later stages of development, and playing a key role in defining tooth number within the mature dentition [18-20]. Here, we review contemporary data relating to the role of Shh during odontogenesis in jawed vertebrates, describe the multiple actions of this signaling protein at the cellular level, and highlight the more recent identification of Shh as a potential primitive stem cell regulator in the murine incisor [21]. 


\section{Shh Pathway Components and Signaling Activity}

Shh transcription is consistently restricted to the epithelial component of the developing tooth germ, from initiation through to root development (Figure 1). However, the secreted signaling protein has been shown to diffuse within the surrounding epithelium and mesenchyme of the tooth, influencing reciprocal epithelial-mesenchymal signaling between these two embryonic tissue components in both mice and humans $[9,13,16]$. Shh signals through a complex pathway, with the availability and activity of secreted ligand modified at multiple levels in both producing and receiving cells in a tissue-dependent manner. The post-translational modification of Shh involves the addition of cholesterol $[22,23]$ and palmitate [24] groups to the newly synthesized pre-protein. Cholesterol limits the movement of the processed ligand, and creates a higher concentration gradient close to the signal source [25]. Palmitate is required for the formation of a multimeric complex that facilitates Shh diffusion over multiple cell layers [26]. In addition, Shh creates a self-regulatory feedback loop by inducing the transcription of signaling components, such as the receptor Patched1 (Ptch1), Glioma-associated oncogene family members Gli1-2, and the negative regulator Hedgehog-interacting protein (Hhip1). The target genes can be found in both Shh-expressing cells and surrounding tissues, demarcating regions where autocrine and paracrine signaling is active $[9,27,28]$. This multifaceted regulation of Shh is an essential part of defining the correct tissue responses, as it acts as a morphogen whose concentration gradient elicits different tissue responses and cell fates based on their distance from the signal source [28-30].

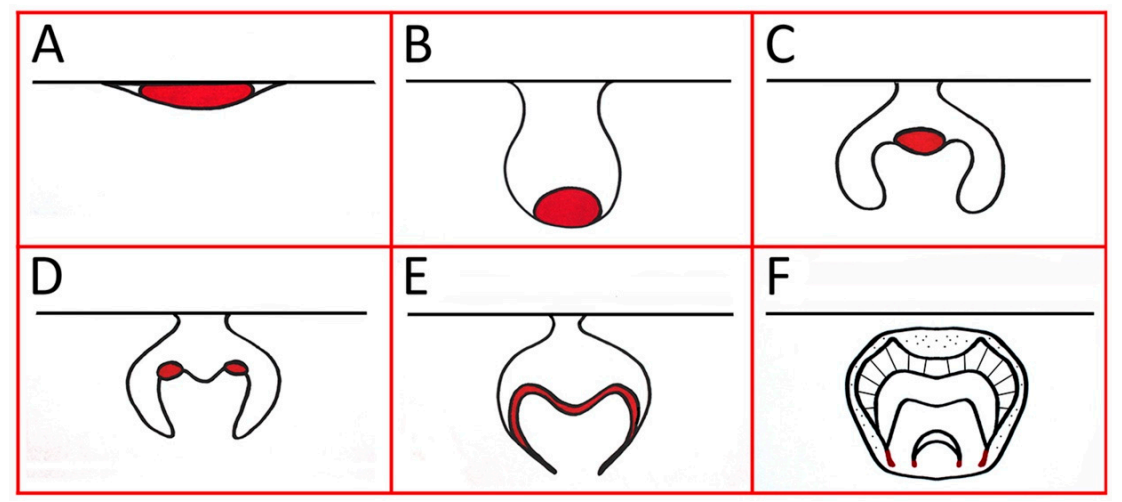

Figure 1. Schematic representation of Shh transcription in the developing tooth (red). (A) Initiation; (B) Early bud stage (at the tip of the bud in enamel knot precursor cells); (C) Early cap stage (in the primary enamel knot); (D) Late cap stage (in the secondary enamel knots); (E) Bell stage (in the internal enamel epithelium, pre-ameloblasts and stratum intermedium); (F) During root development (in Hertwig's epithelial root sheath).

In recent years, the primary cilium has been identified as an important region of the cell that coordinates a number of molecular signaling pathways, including Hedgehog and Wingless-type MMTV integration site family (Wnt) [31]. During signaling, pathway activation occurs following the binding of Shh to the primary receptor Ptch1 [32-34] (Figure 2). In the resting state, Ptch1 accumulates at the cilium, and inhibits transduction through the indirect suppression of Smoothened (Smo), a G-protein coupled receptor-like protein essential for transduction $[35,36]$. Activated Smo then accumulates at the ciliary membrane [37], and effects downstream intracellular signaling through the processing of Gli1-3 transcription factors [33,38,39]. Following pathway activation, Ptch1 rapidly accumulates on the cell surface to buffer signal activity in a ligand-dependent manner [40,41]. The relative availability of bound and unbound receptor is further regulated through the Shh-mediated transcriptional repression of its own co-receptors. These include the GPI-linked membrane glycoprotein Growth arrest-specific 1 (Gas1) [42], as well as the Ig/fibronectin single-pass membrane-spanning cell adhesion proteins Cdon (cell adhesion associated, oncogene regulated) and Boc (cell adhesion associated, oncogene 
regulated) $[43,44]$. Although a vast amount of previous and ongoing research has identified multiple intriguing features of this pathway, a complete understanding of the biochemistry remains elusive.

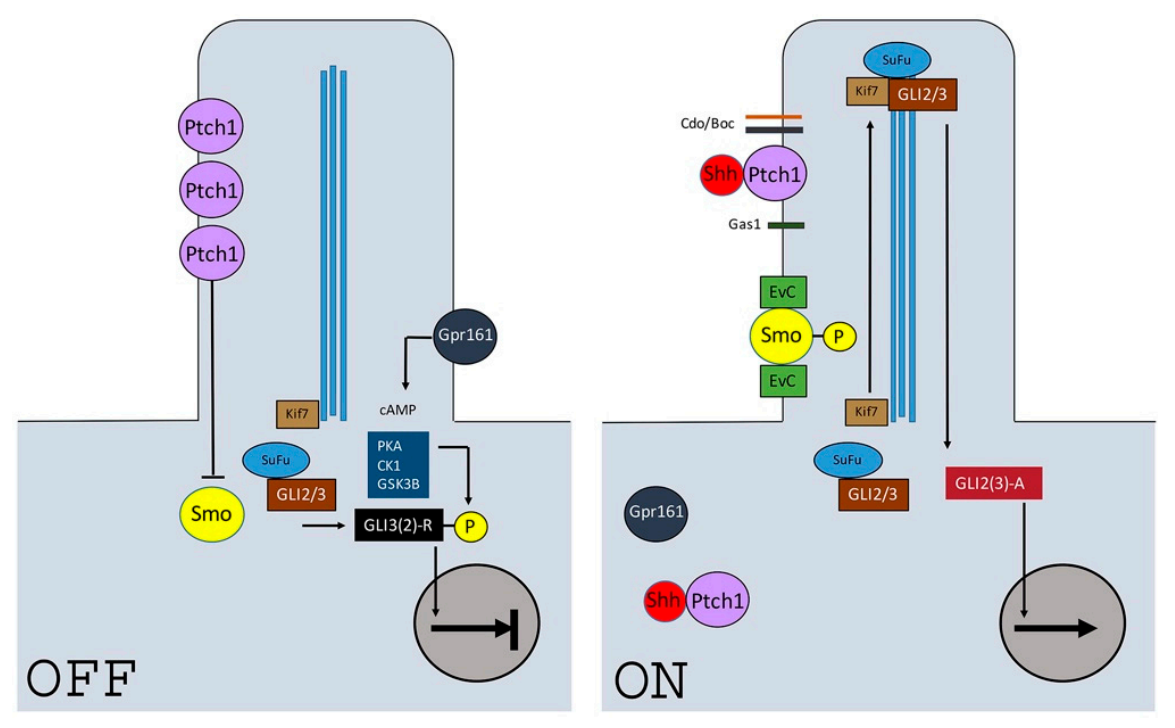

Figure 2. A simple diagrammatic representation of the (known) key events in Shh signaling at the primary cilium. In the absence of signal (OFF), Ptch1 accumulates at the ciliary membrane and represses Smo. GLI proteins are sequestered by Kif7 and Suppressor-of-fused (SuFu), and phosphorylated through the activity of Gpr161, PKA, CK1 and GSK3B. The phosphorylated GLI proteins are proteolytically processed into truncated repressor forms, which act to inhibit transcriptional activation of the pathway. The signaling pathway is activated $(\mathrm{ON})$ through the binding of Shh to Ptch1, which is facilitated by Cdo, Boc and Gas1 co-receptors. The receptor complex is internalized and degraded, which leads to the accumulation of Smo in the ciliary membrane, where it is phosphorylated and interacts with Ellis-van Creveld (EvC) proteins in the basal component of the cilium. The Kif7, $\mathrm{SuFu}$, and GLI complex moves to the tip of the cilium where GLI is concentrated and then transported back to the cytosol where it enters the nucleus as a full length activator of transcriptional targets.

\section{Shh Induces Invagination of the Early Dental Lamina}

During mouse embryonic day (E)11 Shh is expressed in the early dental placodes [8] and has an inverse relationship with $W n t 7 b$, which is expressed in the non-odontogenic epithelium and inhibits Shh. These expression domains define the sites where teeth will and will-not form [17]. Subsequently, the Shh-expressing dental placode undergoes strong vertically-orientated cell division and becomes histologically visible. The placode further stratifies into basal (deeper) and multiple suprabasal (superficial) layers to produce an epithelial thickening, which invaginates into the underlying mesenchyme at around E11.5 and progresses to an early bud by E12.5 [45,46]. After a short period of quiescence, Shh expression becomes localized at the tip of the established tooth bud $[9,15]$.

The repeated expression of $S h h$ in epithelium of the developing tooth prompted early studies investigating the role of this signal pathway during tooth development $[9,14-16,47]$. One of the first investigations demonstrated that the application of ectopic Shh was capable of stimulating crude invagination of both odontogenic and non-odontogenic oral epithelium [9]. These data proved consistent with findings from mandibular explant culture experiments, where the opposite effect was achieved following the inhibition of Shh using the 5E1 blocking antibody [14]. Specifically, a loss of Shh function from E10.5 resulted in the early arrest of tooth development at the epithelial thickening stage, associated with the down-regulation of Ptch1 and a lack of proliferation in deeper regions of the epithelial thickening. Shh mutant mice display severe defects associated with the first branchial arch $[48,49]$, which makes them redundant as a model to study tooth development. To overcome this, mice have been generated using Cre-LoxP-mediated recombination to remove Shh function in the early 
oral epithelium from around E11.75 using a Keratin-14 (K14) promoter. Interestingly, these mice did form epithelial buds at E12.5, but they were associated with wider and shallower invaginations when compared to control teeth [15]. Collectively, these studies provided strong evidence of an inductive and mitogenic role for Shh during the early stages of tooth development.

More recently, the specific requirements for Shh during the progression from placode to bud have been further investigated using explant culture and confocal imaging [20]. A temporal 24-h inhibition and over-expression of Shh and Fibroblast growth factor (Fgf) signaling in mandibular cultures at E10.5 and 11.5 have revealed distinct and independent functions for these pathways in the early tooth germ. The inhibition of Fgf signaling at E11.5 using the pan-Fgf receptor inhibitor SU5402 results in a failure of epithelial stratification and decreased levels of proliferation, with reduced depth in the placodal region. Similarly, Fgf inhibition at E12.5 also produces smaller tooth buds, but even though there is less downward growth, the width of the tooth bud remains unaffected, indicating that Fgf signals drive proliferation, epithelial stratification, and the generation of suprabasal cells, but are likely dispensable for invagination. This study also showed that even though Shh has previously been shown to induce proliferation during the early stages of tooth development, it is more likely to be Fgf signaling that is required and sufficient to drive vertically-orientated cell division at the dental thickening stage. The inhibition of Shh using the Smo-antagonist cyclopamine at E10.5 and 11.5 had no effect on stratification or proliferation, but the tooth buds were shallower and wider. Cellular analysis revealed that these tooth germs lacked columnar-shaped cells and elongated nuclei in basal and suprabasal regions, with the difference most significant in shoulder regions of the invaginating dental lamina. When Shh activity was amplified using the Shh-agonist purmorphamine, the results were narrowed tooth bud necks that invaginated to a much deeper level in comparison to controls. Changes in cellular and nuclear shape are indicative of motile cell behavior, and Shh appears to coordinate the morphogenetic movement of cells required for normal invagination of the tooth germ. Significantly, this is contradictory to previous studies-as no changes in proliferation levels were noted - and it suggests an important role for Shh specifically influencing the cellular rearrangements required for driving the invagination of the early tooth germ [34].

\section{Shh Governs Early Molar Morphogenesis}

After the initial thickening stage, Shh is upregulated at E13.5 in the epithelial bud tip. The intensity of Shh expression subsequently increases a day later at the cap stage, when the primary enamel knot appears $[9,12]$. At the same time, Ptc1, Gli1-2, and Smo are all expressed in partially overlapping domains within both the dental epithelium and the surrounding mesenchyme, but their expression is excluded from the enamel knot [9].

The primary and secondary enamel knots are transient signaling centers [12] that express a number of signaling molecules, including $F g f 3,4$, and 9; Bone morphogenetic protein (Bmp) 2, 4, and 7; Wht10a and 10b; and Shh [12,50-53] and act to define tooth shape [12,54-57]. At E14.5, K14-Cre; Shh conditional knock-out molars show continued dental development, but morphogenesis is significantly disrupted. At this stage, the molars are around 25 per cent smaller than wild type and are dysmorphic, as they fail to obtain a normal cap stage form. Interestingly, these molars also show signs of disrupted bucco-lingual polarisation, as only the remnants of a lingual protrusion are observed. However, Fgf4, $B m p 2$ and $W n t 10 b$ are all expressed in the enamel knot of these teeth, whilst ectopic Wnt10b and Lef1 expression extends lingually. This suggests that the loss of Shh results in a partial change of cell fate, from proliferative to a less proliferative enamel knot-like population on the lingual side. In addition, E14.5 tooth germs are fused with the oral epithelium and lack any clear dental cord connecting the oral epithelium with the invaginating tooth germ. Thereafter, Shh appears to drive polarisation of the tooth in a bucco-lingual axis and induce proliferation in a differential manner, taking part in determining tooth shape [15]. This is supported by the stronger expression of Ptch1 on the lingual side of the cap stage outer enamel epithelium (OEE) $[9,15]$. Furthermore, a molecular investigation of conditional knockouts shows the intact expression of Bmp4, Msx1, and Pax9, providing evidence that during the 
start of morphogenesis, Shh is dispensable for their induction. In contrast, Pit $x 1$ is downregulated and appears to be under the regulation of Shh [15].

The loss of Ellis-van Creveld $(E v C)$ function also results in fusion of the first and second molars, reduced size of the first molar in comparison to the second and single root formations. In addition, $E v C$ appears to be involved in a symmetrical bucco-lingual response to Shh during molar development. Intriguingly, $E v C$ mutant mice show more severe defects on the buccal side rather than the lingual, distinguishing them from K14-Cre; Shh mice. This may be due to the different origins of the buccal and lingual tissues from the ectoderm and endoderm, respectively; as patients with EvC syndrome do not present with any known anomalies associated with endoderm-derived tissues [58,59]. At E14.5, the asymmetric molar phenotype is accompanied by a buccal shift in expression of Shh, Wnt10b, and Lef1-expressing enamel knot cells and a lingual shift of Fgf4. Although Shh expression remains robust in the epithelium, Ptch1 and Gli1 are absent from the surrounding mesenchyme, underlining that Shh signaling is disrupted in $\mathrm{EvC}$ mutants [58]. When $\mathrm{EvC}$ forms a complex with $\mathrm{EvC2}$ it localises to the cilium, where it interacts with Smo and controls dissociation of the negative Hedgehog regulator Suppressor-of-fused (SuFu) from Gli3, and thus Gli3 movement into the cilia (see Figure 2) [60].

\section{A Lack of Shh Results in a Failure of Ameloblast Polarization}

The process of cytodifferentiation begins in the tooth germ at the bell stage, around E18 in a mouse. At this stage, the future tooth consists of an epithelial enamel organ (EEO) and the dental mesenchyme. The EEO is a complex structure consisting of the inner enamel epithelium (IEE), secondary enamel knots, and the OEE, which is separated from the IEE by an internally-located stratum intermedium (SI) and stellate reticulum (SR). Polarized pre-odontoblasts situated adjacent to the IEE within the mesenchymal compartment differentiate and secrete predentin, which induces the IEE to differentiate into pre-ameloblasts [61,62]. Shh is strongly expressed in the IEE with Ptch1 in the underlying mesenchyme just prior to the differentiation of the pre-odontoblasts $[16,63]$. The inductive signal for odontoblast differentiation is known to originate from the IEE, and thereafter the spatio-temporal expression pattern of Shh and Ptch1 implicates Shh as having a role in transmitting the required signal between these two tissue components, as well as being a marker for pre-ameloblasts.

Regardless of the strong expression of Shh in the IEE, K14-Cre; Shh mice do have differentiated pre-odontoblasts and pre-ameloblasts in the developing tooth at E19.5, with these cells expressing known markers that demonstrate functionality. Furthermore, a secreted enamel and dentin matrix is evident between the two cell populations. However, the cellular architecture is disrupted, as the odontoblasts fail to form a continuous monolayer, and only a proportion of these cells polarise and elongate. Similarly, the differentiating ameloblasts remain small and cuboidal, in contrast to the elongated and polarised cell shapes seen in control tooth germs [15]. The conditional removal of Shh responsiveness exclusively from the oral epithelium by inactivation of Smo under the K14 promoter (K14-Cre; Smo) results in the normal polarisation of the mesenchymally-derived pre-odontoblasts, but disrupted polarisation of the pre-ameloblasts, and hypocellularity of the SR and SI. An abnormal cytoskeletal organisation of the pre-ameloblasts is seen, associated with a lack of Ptch2 and Gli1 accumulation in the intracellular space on the basal side. This implicates a possible role for the stratum intermedium in providing a guiding signal for the subcellular trafficking of proteins that takes place during polarisation. In addition, K14-Cre; Smo mice show an absence of $\beta$-tubulin accumulation, and a polarized cytoplasmic localisation of E-Cadherin and Zonula Occludens-1 (ZO-1). This provides evidence of a lack of specialised junctional complexes that, together with microtubules, are important for establishing the cell polarity and the apical and basolateral domains. Further analysis has demonstrated reduced proliferation as well as early loss of the phosphorylated histone $\mathrm{H} 3(\mathrm{PH}-\mathrm{H} 3)$ protein (a known marker of mitosis) and the Shh-induced cyclinD1. This indicates that decreased proliferation levels could be a consequence of premature exit from the cell cycle, and cytodifferentiation of ameloblast progenitors before predentin secretion. This suggests that Shh regulates the cell cycle and exerts its mitogenic role by promoting cyclin $D 1$ transcription to control the G1/S transition [16]. These 
studies have highlighted how Shh guides cytoskeletal organisation and promotes the arrangement of cell-cell junctional complexes, not only at sites of mesenchymal-epithelial interaction, but also within epithelial cell populations.

\section{Disrupted Shh Signaling Causes Molar Fusion and Altered Cusp Morphology}

The signaling molecules expressed in the enamel knot regulate morphogenesis by diffusing through the surrounding epithelial and mesenchymal tissues, where they are responsible for defining appropriate molecular and cellular responses. These molecular signals can positively and negatively interact at multiple levels to polarise and pattern tissues.

An elaborate model, based on Alan Turing's reaction-diffusion principles guiding pattern formation, has been redrawn to potentially explain cuspal patterning by Shh and Wnt signaling [18]. At E14.5, Shh, Wnt10a, and Wnt10b are similarly expressed in the enamel knot and secreted laterally to the surrounding tissues [50]. Whilst Wnt induces its own transcription factor Lef1 in immediate proximity to its source and positively regulates Shh via Fgf3 and Fgf4, Shh ligand has the ability to diffuse faster than Wnt, and travels outside of the Wnt-created Lef1 zone, where it has an opposing effect. Shh induces the expression of the Wnt inhibitor Wise, indirectly limiting the activity of Wnt and simultaneously creating the odontogenic Lef1 and non-odontogenic Wise zones [16,18,64-66]. In this Shh-Wise-Wnt feedback model, Wnt acts as an activator; Shh a mediator; and Wise an inhibitor [18]. Consistently, a loss of Wise function [54] and multiple mouse models with reduced Shh signaling activity $[15,16,18]$ have severely disrupted cuspal patterning in the molar dentition, manifesting as enlarged and fused molar teeth with multiple smaller cusps.

The importance of temporal Shh signaling in molar development has more recently been investigated by blocking Shh activity in utero at different time-points between E10-18 with 5E1 intra-peritoneal injection. When injections are carried out at E10 or 12, the non-odontogenic field is absent only between first and second molars, which are fused together. If injections are carried out at E16 the same effect moves further distally in the dental arch, with the second and third molars fused. This correlates with the sequential development of these teeth, progressing along the mesio-distal axis. This phenotype is associated with altered Wnt signaling domains between the fusing molars, as demonstrated by an expanded Sp5 expression across the first and second molars, and in contrast to controls that demonstrated the separate molar domains of Sp5. Interestingly, reduced levels of Shh and increased levels of Wnt were associated with the accelerated development of the second molars in comparison to controls [18].

\section{Shh Influences Tooth Root Development}

Shh and constituent members of the signalling pathway are also expressed during early development of the molar tooth root in the mouse. Specifically, Shh transcripts localise to the epithelial cells of Hertwig's epithelial root sheath, whilst Smo, Ptch1, and Gli are expressed in the apical mesenchyme of the associated dental papilla and follicle [11]. The analysis of mesenchymal dysplasia (mes) mice, which harbour an abnormal C-terminus associated with Ptch1, has shown repressed proliferation, shorter roots and a disturbed molar eruption [67]. More recently, it has been shown that regulating appropriate levels of Shh signaling is crucial for the normal growth and development of the root, with both reduced and increased signal levels producing reduced levels of proliferation, and ultimately, root length. Moreover, levels of Hedgehog activity are regulated by nuclear factor I/C (Nfic), which binds Hhip1 in the apical papilla [68]. Signifcantly, Nfic mutant mice also develop short molar roots [69].

\section{Shh and Its Role in Defining the Tooth Formula}

In contrast to humans, mice have only a single incisor and three molars in each dental quadrant, separated by a non-odontogenic diastema. However, at the earliest stages of odontogenesis, multiple epithelial thickenings accompanied by the expression of Shh are identifiable in the diastema region. 
These vestigial swellings only progress to a thickening or rudimentary bud stage, and thereafter regress via apoptosis with the simultaneous disappearance of Shh expression [70-74]. Interestingly, several mouse models with disrupted Shh, Wnt, Fgf, and Bmp signaling levels develop supernumerary teeth. These teeth typically arise from the most posterior rudimentary swelling, referred to as R2, and which during normal mouse development fuse with the main cap stage's first molar [71,73]. Although these premolar-like supernumeraries have been described as evolutionary remnants (the non-odontogenic diastema has been a prevailing feature of mice for over 50 million years) $[19,55,73]$, they provide an excellent model to study how different signaling cascades interact to control tooth formula, by either inducing or suppressing the progression of tooth development, and defining the boundaries between odontogenic and non-odontogenic fields.

Whereas a reduction or loss of Shh signaling activity has been associated with molar fusion $[15,16,18]$, increased activity in the diastema can result in altered molar field patterning and supernumerary tooth formation (Figure 3) [19,55]. Indeed, multiple knockout mouse models have identified the upregulation of $S h h$ in the diastema, which as a primary or secondary response results in supernumerary tooth formation $[38,47,54]$, and places $S h h$ as a downstream target $[54,55]$. These studies demonstrate how a complex regulatory network-consisting of its own as well as other molecular signaling cascade members-is responsible for defining the pivotal threshold levels of Shh for the normal progression of tooth development.
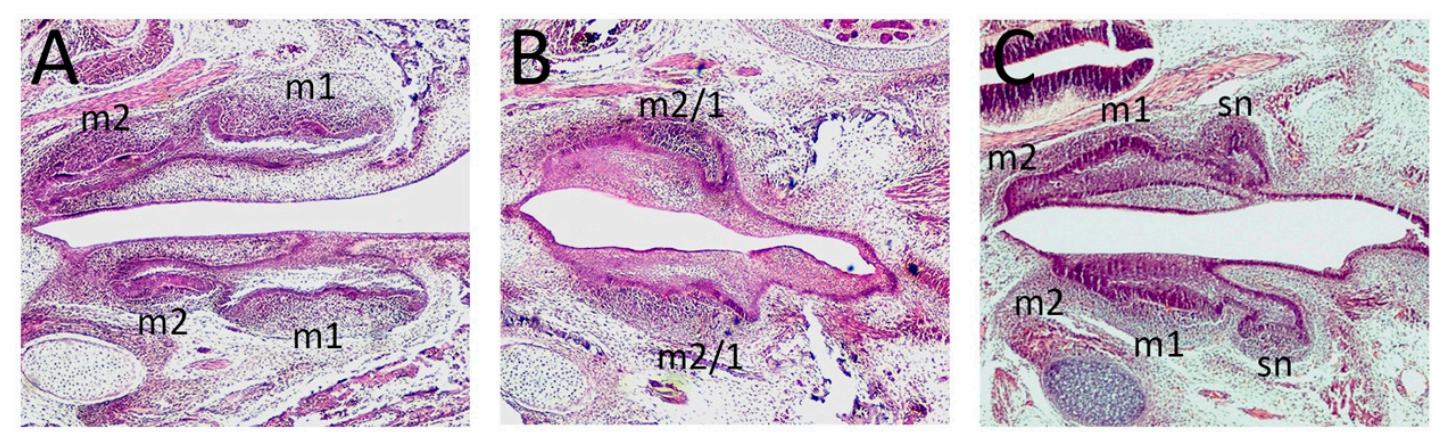

Figure 3. Disrupted Shh signaling and early tooth development. (A-C) Para-sagittal sections of the developing maxillary and mandibular molar dentition in (A) E16.5 Wild type; (B) E16.5 CreER ${ }^{\mathrm{TM}}$; Shh mutant; (C) E15.5 Gas1 mutant embryos. In the wild type embryo, the first molars (m1) are at the late cap/early bell stage of development and the second molars (m2) are at the early cap stage. In CreER ${ }^{\mathrm{TM}}$; Shh mutant embryos, Shh signaling has been abrogated from E10.5 following the administration of Tamoxifen, with fusion between the first and second mandibular molars (m1/m2). In the Gas 1 mutant, $\mathrm{m} 1$ are at the late cap stage and the $\mathrm{m} 2$ tooth germs are just beginning to form an early cap. However, a supernumerary premolar tooth (sn) is present in mesial to $\mathrm{m} 1$ in both quadrants.

Shh also negatively regulates transcription of the co-receptors Gas1, Cdon, and Boc, which are typically expressed at some distance from the signal source, and act in a reciprocal manner to Ptch1 [42,75]. In peripheral regions of the Shh signaling domain where protein levels are low, the increased transcription of these co-receptors is thought to promote signaling in receiving cells, and help achieve appropriate threshold levels for signal transduction in the peripheral regions of the signaling domain [42,76-79]. Interestingly, Gas1 seems to influence Shh in a context-dependent manner: it positively regulates signaling in the facial midline and neural tube $[42,76,78]$, whilst seemingly having an opposite inhibitory role in the early jaw $[19,47]$. During early tooth development, Gas1 is abundant in the surrounding mesenchyme of early tooth germs and in the non-odontogenic diastema, expressed mainly in a reciprocal manner to Ptch1, and sharing only small areas of overlapping expression in the peripheral regions of their respective domains. When Gas1 is over-expressed in the non-odontogenic diastema it downregulates Ptch1, which suggests an important early regulatory mechanism that restricts Shh activity to the tooth-forming regions of the mandible [47]. This is consistent with the 
molar phenotype of Gas1 mutant mice, which demonstrates how an absence of Gas1 allows the diffusion of Shh protein further away from its source. This results at E12.5 in the presence of ectopic protein in the diastema, and an accompanied increased expression of Ptch1. Significantly, Gas1 mutant mice present with single premolar-like supernumeraries located mesial to the first molars, which further supports the concept of Gas1 acting as an additional inhibitor required for limiting Shh activity to the tooth-forming regions [19]. The high-level regulation of Shh signaling in the tooth is further demonstrated by the strong expression of Hhip1 in the peripheral odontogenic mesenchyme [27]. Hhip1 encodes a membrane glycoprotein that can also bind and sequester Shh [80], although to date it only seems to retain an essential function in root development [68]. Primary cilia protein components also generally exert a negative regulatory effect on Shh activity, and seem to play a role in repressing tooth formation. Mice mutants for the cilia intraflagellar transport (IFT) protein (IFT88 or Polaris) show an upregulation of Shh signaling activity, and form ectopic premolar-like teeth in the diastema [19]. However, the phenotypic consequences of a disrupted ciliary function have to be interpreted within the wider context of their potential effect on other signal pathways, including Wnt transduction.

The Sprouty (Spr) gene family encode universal receptor tyrosine kinase signaling (RTK) inhibitors that are induced by Fgfs, but which inhibit Fgf signaling to provide an important negative feedback regulatory mechanism [81]. Fgfs are found at multiple sites in the developing tooth and at multiple stages, with expression domains extending into the dental epithelium. There, they become localised to the enamel knot ( $F g f 4$ and $F g f 9$ ) and surrounding mesenchyme ( $F g f 3$ and $F g f 10$ ), including the diastema (Fgf10). Interestingly, Spr2 and Spr4 mutant mice form premolar-like diastema supernumeraries similar to those seen in Gas1 and Polaris mutants [55]. Predictably, Spr2 and Spr4 mutants demonstrate ectopic Fgf activity, which spatio-temporally correlates with the formation of these supernumeraries. There is also the continued expression of Shh in R2 at E14.5, providing further evidence that Fgfs act upstream of Shh in the tooth and positively regulate its activity. Whereas Spr4 is found exclusively in the surrounding mesenchyme, Spr 2 localizes more prominently to the bud epithelium. However, some activity is also present in the mesenchyme surrounding the developing first molar. Thereafter, Spr2 is considered to be required for the indirect inhibition of Fgf-induced Shh expression, and in normal development acts to suppress the development of the first molar [55]. In addition, Fgf and Wnt pathways form an important reciprocal signaling network between the epithelium and the mesenchyme at this stage, because Fgf4 transcription relies on Wnt-induced Lef1 [65].

Interestingly, even though diastema teeth develop in Spr2 and Spr4 mutants, they do not significantly affect first molar cusp morphology, indicating that Sprouty gene activity is more notably involved in defining tooth number rather than cusp patterning [55]. This is distinct from Wise-mediated loss of Wnt inhibition, which results in both the development of diastema supernumerary teeth with variable penetrance and altered cusp morphology [54]. The relationship between Shh and Wnt signaling during supernumerary tooth formation has been further investigated by generating Wise+/-; Shh/GFPCre/+ compound mice, which exhibit reduced Shh dosage. These mice also display a supernumerary tooth phenotype that can be rescued by increasing Shh levels through a partial loss of Ptch1 function, or reducing Wnt signaling levels by reducing Lrp6. In turn, when Shh is downregulated, Wnt signaling is upregulated, indicative of a Shh negative-feedback loop required for controlling the levels of Wnt signaling. Altogether, there is strong evidence available to suggest that the relative expression levels of Shh and Wnt play a major role in coordinating multiple patterning processes, and that an appropriate balance between these pathways is crucial for the normal progression of tooth development.

\section{Shh as a Regulator of Dental Stem Cells}

Mouse incisors grow continuously throughout life, and have provided a unique model to study the potential surface markers, anatomical location and role of stem cells in tooth development. The cervical loop is a component of the enamel organ that disappears in molars, but prevails in incisors and enables enamel formation to continue in adult mice. Actively proliferating transit amplifying cells 
(TACs) are located close to the cervical loop, and are thought to represent the location of an epithelial stem cell reservoir $[82,83]$. Murine incisor epithelial stem cells can be identified in the incisor based on the expression of specific surface markers, which include Gli1, Bmi1 and Sox2 [83,84]. Investigations in the murine incisor using Gli1-LacZ reporter mice have found such expression (in addition to dental epithelial cells and labial post-mitotic odontoblasts) specifically in the mesenchyme surrounding the neurovascular bundle (NVB) in both arterioles and their surrounding nerves [84]. Interestingly, this expression was not induced by Shh originating from the dental epithelium, but Shh secreted by sensory neurons of the trigeminal ganglion, whose axons also innervate the inferior alveolar nerve and adult lower incisors. In the incisor mesenchyme, Gli1+ cells strongly overlap with H2BGFP-labelled quiescent stem cells, supporting Gli1+ as being a stem cell marker. The Gli1+ and H2BGFP double-labelled cells do not express many of the common stem cell-related surface markers such as CD105, CD73, NG2, CD146, CD44, or Sca1. However, culture-based studies using Gli1-CE; Tdtomato mice have shown that these cells rapidly lose Gli1 expression when communication with the NVB is lost, and can subsequently differentiate into different MSC subpopulations that express CD146, CD105, Sca1, and CD73. In addition, upon hard tissue injury, Gli1+ cells can give rise to odontoblasts [21]. Similarly to Shh being critical for an osteoblast lineage commitment [85], it may also be essential for an odontogenic commitment of incisor stem cells through primitive Gli1+ cells giving rise to pericytes, which consecutively upon injury are stimulated to differentiate into odontoblasts. Although the inhibition of Shh signaling in mice fed for one month with a Hedgehog-antagonist did reduce dentin formation, it did not have any significant impact on mesenchymal cell proliferation, apoptosis, or the number of label-retaining slow cycling stem cells [84]. Therefore, Shh derived from sensory neurons has a key role in both murine adult incisor homeostasis and hard tissue tissue repair, but is not required for stem cell proliferation and maintenance. Significantly, Gli1 + cells are also found elsewhere in the body surrounding the arteries, and raise the possibility that they could also mark stem cells in other organs [86].

\section{Shh as a Universal Marker of Vertebrate Tooth Development}

Although the majority of tooth development research has focused on the murine dentition, it is clear that Shh is also a conserved marker of tooth development, from initiation through to morphogenesis, amongst all toothed vertebrates including fish, reptiles, and humans [4-9]. Even in the phylogenetically basal cartilaginous fishes, the Chondrichthyes (which include sharks, rays and holocephalans), shh is a key epithelial marker of tooth development and morphogenesis [6,7]. In the embryonic shark (Scyliorhinus canicula), shh is expressed in a restricted band along the oral jaw prior to tooth initiation [6] (Figure 4). This expression is an indicator of emerging dental competence in the pre-lamina epithelium or odontogenic band [6,87]. This early shh expression in the odontogenic band is obvious across vertebrate taxa, and demarcates the spatial restriction of tooth territories. The comparative appearance of shh expression in this region also confirms a variability that highlights the early diversity of tooth patterning among vertebrate clades [88].

Following initial establishment of the odontogenic band and the first appearance of shh expression, the first teeth in the shark jaw manifest as superficial thickened placodes in a similar pattern of emergence to the teeth of other vertebrates, such as reptiles and mammals. During this process of shark tooth placode maturation, shh expression persists within the epithelial placode (the early tooth bud) as the underlying mesenchyme begins to condense and trigger the cap stage of tooth morphogenesis (Figure 4). Here, the epithelial component surrounds the mesenchymal core or dental papilla in a characteristic form that appears to be highly conserved among all vertebrates. At this stage, shh expression becomes clearly localized to the apical cells of the tooth bud (Stage 32; Figure 4), which is indicative of the regions attributed to the enamel knot signaling centres that govern tooth shape in mammals [6]. In the shark, defined regions of shh expression (and the expression of other known enamel knot markers) in the presumptive primary enamel knot cells show a uniformity, and therefore a conservation of primary enamel knot signaling among vertebrates. This indicates that not only 
are the early phases of vertebrate tooth initiation conserved, but also that the later stages of tooth morphogenesis, and therefore the genetic programme (including Shh signaling) for general vertebrate tooth development, is an evolutionarily stable process.
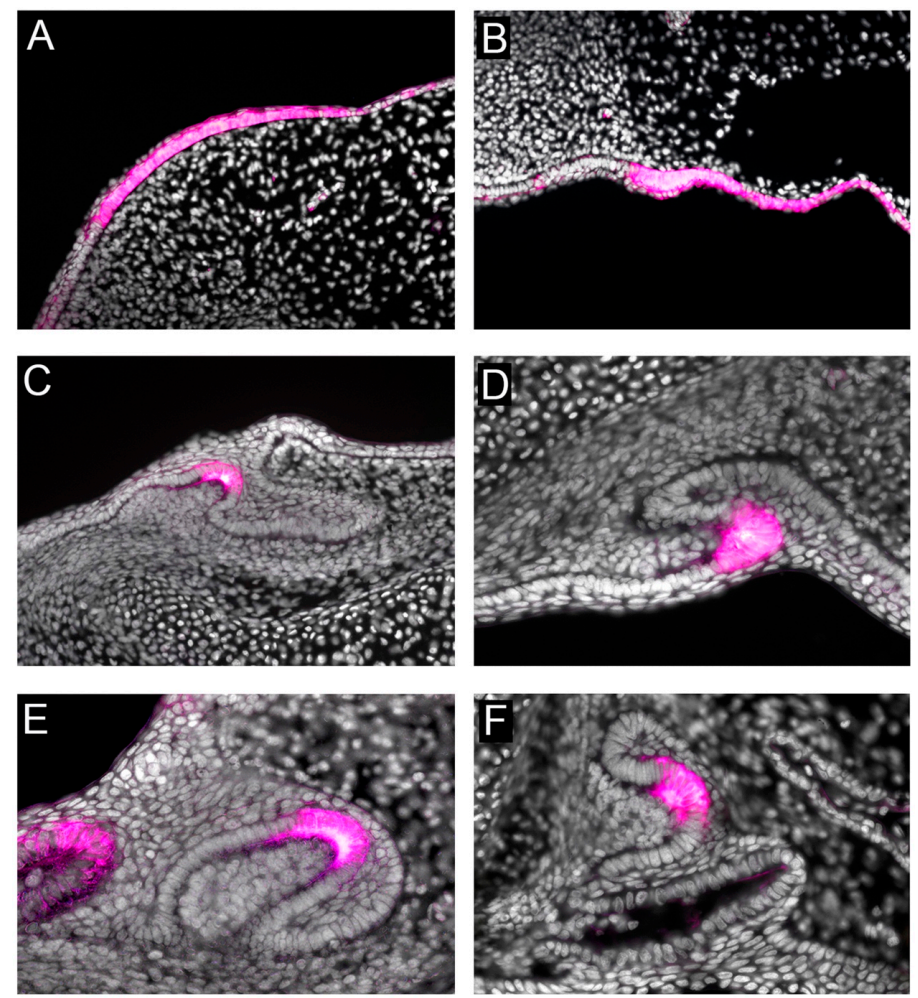

Figure 4. Conserved shh expression in shark tooth initiation and successional morphogenesis. Expression of shh in the odontogenic band marks the onset of dental competence in the shark (Scyliorhinus stellaris) lower jaw (A) and upper jaw (B). Development of the first tooth and subsequent morphogenesis in Scyliorhinus canicula is superficial with shh expression restricted to the dental epithelium at the apical cusp, lower jaw (C) and upper jaw (D). Dental lamina epithelium continues to invaginate lingual to the first tooth, from which new successional teeth will develop in the lower jaw (E) and upper jaw (F). New successional teeth in the shark continue to express shh during morphogenesis (E,F). Note shh is not expressed in the epithelial dental lamina away from developing teeth, and its expression is restricted to the enamel knot-like cells at the apex of each new tooth throughout morphogenesis. False colour, (magenta) gene expression; nuclear counterstain DAPI (white).

Following the establishment of the first tooth and the subsequent territories of the elasmobranch first generation dentition, the dental epithelial cells lingual to the first tooth continue to proliferate and invaginate lingually into the mesenchyme. This invagination oral to the jaw cartilages produces the early dental lamina, which is the continuous jaw-wide epithelial unit that plays a crucial role in the production of successional teeth, and houses progenitor cells for successional tooth development [89]. Sharks, and their cartilaginous relatives (the elasmobranchs), offer a novel tooth and jaw complex to study the locations where teeth develop and attach superficially to jaw cartilages via connective tissues rather than being anchored in a bony jaw as seen in bony vertebrates (Osteichthyans). This condition in elasmobranchs permits a unique flexibility during tooth development, and importantly during the production of multiple tooth generations, where each tooth position along the jaw has a related lingual succession of teeth (family) at various stages of development housed within a continuous dental lamina. Sharks are polyphyodont vertebrates with continuous tooth regeneration occurring throughout life [89]; therefore, several generations of teeth are present ahead of functions within the epithelial dental lamina (Figure 4). As each new tooth generation is initiated within the deeply invaginated distal 
tip of the dental lamina (successional lamina), shh is expressed within the dental epithelium, where it becomes more restricted to the cells of the primary enamel-like cell clusters as the tooth matures (Figure 4). Intriguingly, although shh is expressed in the odontogenic band, and therefore the early dental epithelium essential for first generation tooth formation, in non-mammalian polyphyodont species it is not expressed within the dental lamina (aside from the cells associated with the cusps of developing teeth). Importantly, it is absent from regions of the dental lamina that are actively initiating new tooth generation, the successional lamina. This characteristic of polyphyodonty is observed in teleost fishes [90], chondrichthyan fishes [6], and in reptilian models [5]. This suggests that although shh—and more generally, Hedgehog signaling —is a requirement for the normal development of first generation teeth, it is not essential to the subsequent development of successional tooth families in non-mammalian polyphyodont animals. This indicates a crucial role for Shh signaling during first tooth initiation. However, after the dental epithelium becomes competent for tooth formation, the wider dental epithelium (dental lamina, and successional lamina) is no longer dependent on shh for tooth production.

\section{Conclusions}

The current data suggests a key role for Shh signaling in tooth development that is complex, acts at multiple stages, coordinates various cellular processes and is relevant for multiple species. These processes are independently regulated and are involved in inducing Shh-mediated proliferation, cell polarisation, differentiation, morphogenesis and patterning. Shh interacts with several other signaling pathways at the molecular level, particularly Fgf and Wnt, to ensure the normal progression of tooth development up to and beyond the bud stage. In addition, signal transduction not only activates downstream target genes, but also inhibits pathway activity. This provides an important regulatory mechanism to ensure that signal levels achieve the appropriate cellular response.

Acknowledgments: M.S. and G.M.X. in the laboratory of M.T.C. are supported by the European Orthodontic Society and Academy of Medical Sciences (M.S.) and Academy of Medical Sciences (G.M.X.). The laboratory of G.J.F. is supported by the Natural Environment Research Council (NERC) Standard Grant NE/K014595/1 and Leverhulme Trust Research Grant RPG-211. We thank Liam Rasch for performing the in situ hybridization shown in Figure 4.

Conflicts of Interest: The authors declare no conflict of interest.

\section{References}

1. Briscoe, J.; Therond, P.P. The mechanisms of hedgehog signalling and its roles in development and disease. Nat. Rev. Mol. Cell Biol. 2013, 14, 418-431. [CrossRef] [PubMed]

2. Ingham, P.W.; McMahon, A.P. Hedgehog signaling in animal development: Paradigms and principles. Genes Dev. 2001, 15, 3059-3087. [CrossRef] [PubMed]

3. Xavier, G.M.; Seppala, M.; Barrell, W.; Birjandi, A.A.; Geoghegan, F.; Cobourne, M.T. Hedgehog receptor function during craniofacial development. Dev. Biol. 2016, 415, 198-215. [CrossRef] [PubMed]

4. Buchtova, M.; Handrigan, G.R.; Tucker, A.S.; Lozanoff, S.; Town, L.; Fu, K.; Diewert, V.M.; Wicking, C.; Richman, J.M. Initiation and patterning of the snake dentition are dependent on sonic hedgehog signaling. Dev. Biol. 2008, 319, 132-145. [CrossRef] [PubMed]

5. Handrigan, G.R.; Richman, J.M. Autocrine and paracrine shh signaling are necessary for tooth morphogenesis, but not tooth replacement in snakes and lizards (squamata). Dev. Biol. 2010, 337, 171-186. [CrossRef] [PubMed]

6. Rasch, L.J.; Martin, K.J.; Cooper, R.L.; Metscher, B.D.; Underwood, C.J.; Fraser, G.J. An ancient dental gene set governs development and continuous regeneration of teeth in sharks. Dev. Biol. 2016, 415, 347-370. [CrossRef] [PubMed]

7. Smith, M.M.; Fraser, G.J.; Chaplin, N.; Hobbs, C.; Graham, A. Reiterative pattern of sonic hedgehog expression in the catshark dentition reveals a phylogenetic template for jawed vertebrates. Proc. Biol. Sci. 2009, 276, 1225-1233. [CrossRef] [PubMed] 
8. Bitgood, M.J.; McMahon, A.P. Hedgehog and bmp genes are coexpressed at many diverse sites of cell-cell interaction in the mouse embryo. Dev. Biol. 1995, 172, 126-138. [CrossRef] [PubMed]

9. Hardcastle, Z.; Mo, R.; Hui, C.C.; Sharpe, P.T. The shh signalling pathway in tooth development: Defects in gli2 and gli3 mutants. Development 1998, 125, 2803-2811. [PubMed]

10. Iseki, S.; Araga, A.; Ohuchi, H.; Nohno, T.; Yoshioka, H.; Hayashi, F.; Noji, S. Sonic hedgehog is expressed in epithelial cells during development of whisker, hair, and tooth. Biochem. Biophys. Res. Commun. 1996, 218, 688-693. [CrossRef] [PubMed]

11. Khan, M.; Seppala, M.; Zoupa, M.; Cobourne, M.T. Hedgehog pathway gene expression during early development of the molar tooth root in the mouse. Gene Expr. Patterns 2007, 7, 239-243. [CrossRef] [PubMed]

12. Vaahtokari, A.; Åberg, T.; Jernvall, J.; Keranen, S.; Thesleff, I. The enamel knot as a signaling center in the developing mouse tooth. Mech. Dev. 1996, 54, 39-43. [CrossRef]

13. Hu, X.; Zhang, S.; Chen, G.; Lin, C.; Huang, Z.; Chen, Y.; Zhang, Y. Expression of shh signaling molecules in the developing human primary dentition. BMC Dev. Biol. 2013, 13, 11. [CrossRef] [PubMed]

14. Cobourne, M.T.; Hardcastle, Z.; Sharpe, P.T. Sonic hedgehog regulates epithelial proliferation and cell survival in the developing tooth germ. J. Dent. Res. 2001, 80, 1974-1979. [CrossRef] [PubMed]

15. Dassule, H.R.; Lewis, P.; Bei, M.; Maas, R.; McMahon, A.P. Sonic hedgehog regulates growth and morphogenesis of the tooth. Development 2000, 127, 4775-4785. [PubMed]

16. Gritli-Linde, A.; Bei, M.; Maas, R.; Zhang, X.M.; Linde, A.; McMahon, A.P. Shh signaling within the dental epithelium is necessary for cell proliferation, growth and polarization. Development 2002, 129, 5323-5337. [CrossRef] [PubMed]

17. Sarkar, L.; Cobourne, M.; Naylor, S.; Smalley, M.; Dale, T.; Sharpe, P.T. Wnt/shh interactions regulate ectodermal boundary formation during mammalian tooth development. Proc. Natl. Acad. Sci. USA 2000, 97, 4520-4524. [CrossRef] [PubMed]

18. Cho, S.W.; Kwak, S.; Woolley, T.E.; Lee, M.J.; Kim, E.J.; Baker, R.E.; Kim, H.J.; Shin, J.S.; Tickle, C.; Maini, P.K.; et al. Interactions between shh, sostdc1 and wnt signaling and a new feedback loop for spatial patterning of the teeth. Development 2011, 138, 1807-1816. [CrossRef] [PubMed]

19. Ohazama, A.; Haycraft, C.J.; Seppala, M.; Blackburn, J.; Ghafoor, S.; Cobourne, M.; Martinelli, D.C.; Fan, C.M.; Peterkova, R.; Lesot, H.; et al. Primary cilia regulate shh activity in the control of molar tooth number. Development 2009, 136, 897-903. [CrossRef] [PubMed]

20. Li, J.; Chatzeli, L.; Panousopoulou, E.; Tucker, A.S.; Green, J.B. Epithelial stratification and placode invagination are separable functions in early morphogenesis of the molar tooth. Development 2016, 143, 670-681. [CrossRef] [PubMed]

21. Zhao, H.; Feng, J.; Seidel, K.; Shi, S.; Klein, O.; Sharpe, P.; Chai, Y. Secretion of shh by a neurovascular bundle niche supports mesenchymal stem cell homeostasis in the adult mouse incisor. Cell Stem Cell 2014, 14, 160-173. [CrossRef] [PubMed]

22. Porter, J.A.; Ekker, S.C.; Park, W.J.; von Kessler, D.P.; Young, K.E.; Chen, C.H.; Ma, Y.; Woods, A.S.; Cotter, R.J.; Koonin, E.V.; et al. Hedgehog patterning activity: Role of a lipophilic modification mediated by the carboxy-terminal autoprocessing domain. Cell 1996, 86, 21-34. [CrossRef]

23. Porter, J.A.; von Kessler, D.P.; Ekker, S.C.; Young, K.E.; Lee, J.J.; Moses, K.; Beachy, P.A. The product of hedgehog autoproteolytic cleavage active in local and long-range signalling. Nature 1995, 374, 363-366. [CrossRef] [PubMed]

24. Pepinsky, R.B.; Zeng, C.; Wen, D.; Rayhorn, P.; Baker, D.P.; Williams, K.P.; Bixler, S.A.; Ambrose, C.M.; Garber, E.A.; Miatkowski, K.; et al. Identification of a palmitic acid-modified form of human sonic hedgehog. J. Biol. Chem. 1998, 273, 14037-14045. [CrossRef] [PubMed]

25. Saha, K.; Schaffer, D.V. Signal dynamics in sonic hedgehog tissue patterning. Development 2006, 133, 889-900. [CrossRef] [PubMed]

26. Zeng, X.; Goetz, J.A.; Suber, L.M.; Scott, W.J., Jr.; Schreiner, C.M.; Robbins, D.J. A freely diffusible form of sonic hedgehog mediates long-range signalling. Nature 2001, 411, 716-720. [CrossRef] [PubMed]

27. Cobourne, M.T.; Sharpe, P.T. Expression and regulation of hedgehog-interacting protein during early tooth development. Connect. Tissue Res. 2002, 43, 143-147. [CrossRef] [PubMed]

28. Cohen, M.; Kicheva, A.; Ribeiro, A.; Blassberg, R.; Page, K.M.; Barnes, C.P.; Briscoe, J. Ptch1 and gli regulate shh signalling dynamics via multiple mechanisms. Nat. Commun. 2015, 6, 6709. [CrossRef] [PubMed] 
29. Fan, C.M.; Porter, J.A.; Chiang, C.; Chang, D.T.; Beachy, P.A.; Tessier-Lavigne, M. Long-range sclerotome induction by sonic hedgehog: Direct role of the amino-terminal cleavage product and modulation by the cyclic amp signaling pathway. Cell 1995, 81, 457-465. [CrossRef]

30. Harfe, B.D.; Scherz, P.J.; Nissim, S.; Tian, H.; McMahon, A.P.; Tabin, C.J. Evidence for an expansion-based temporal shh gradient in specifying vertebrate digit identities. Cell 2004, 118, 517-528. [CrossRef] [PubMed]

31. Bangs, F.; Anderson, K.V. Primary cilia and mammalian hedgehog signaling. Cold Spring Harb. Perspect. Biol. 2017, 9. [CrossRef] [PubMed]

32. Goodrich, L.V.; Milenković, L.; Higgins, K.M.; Scott, M.P. Altered neural cell fates and medulloblastoma in mouse patched mutants. Science 1997, 277, 1109-1113. [CrossRef] [PubMed]

33. Haycraft, C.J.; Banizs, B.; Aydin-Son, Y.; Zhang, Q.; Michaud, E.J.; Yoder, B.K. Gli2 and gli3 localize to cilia and require the intraflagellar transport protein polaris for processing and function. PLoS Genet. 2005, 1, e53. [CrossRef] [PubMed]

34. Tukachinsky, H.; Kuzmickas, R.P.; Jao, C.Y.; Liu, J.; Salic, A. Dispatched and scube mediate the efficient secretion of the cholesterol-modified hedgehog ligand. Cell Rep. 2012, 2, 308-320. [CrossRef] [PubMed]

35. Taipale, J.; Cooper, M.K.; Maiti, T.; Beachy, P.A. Patched acts catalytically to suppress the activity of smoothened. Nature 2002, 418, 892-897. [CrossRef] [PubMed]

36. Zhang, X.M.; Ramalho-Santos, M.; McMahon, A.P. Smoothened mutants reveal redundant roles for shh and ihh signaling including regulation of $1 / \mathrm{r}$ asymmetry by the mouse node. Cell 2001, 105, 781-792. [CrossRef]

37. Corbit, K.C.; Aanstad, P.; Singla, V.; Norman, A.R.; Stainier, D.Y.; Reiter, J.F. Vertebrate smoothened functions at the primary cilium. Nature 2005, 437, 1018-1021. [CrossRef] [PubMed]

38. Aberger, F.; Ruiz, I.A.A. Context-dependent signal integration by the gli code: The oncogenic load, pathways, modifiers and implications for cancer therapy. Semin. Cell Dev. Biol. 2014, 33, 93-104. [CrossRef] [PubMed]

39. Hui, C.C.; Angers, S. Gli proteins in development and disease. Annu. Rev. Cell. Dev. Biol. 2011, 27, 513-537. [CrossRef] [PubMed]

40. Casali, A.; Struhl, G. Reading the hedgehog morphogen gradient by measuring the ratio of bound to unbound patched protein. Nature 2004, 431, 76-80. [CrossRef] [PubMed]

41. Chen, Y.; Struhl, G. Dual roles for patched in sequestering and transducing hedgehog. Cell 1996, 87, 553-563. [CrossRef]

42. Martinelli, D.C.; Fan, C.M. Gas1 extends the range of hedgehog action by facilitating its signaling. Genes Dev. 2007, 21, 1231-1243. [CrossRef] [PubMed]

43. Kang, J.S.; Gao, M.; Feinleib, J.L.; Cotter, P.D.; Guadagno, S.N.; Krauss, R.S. Cdo: An oncogene-, serum-, and anchorage-regulated member of the ig/fibronectin type iii repeat family. J. Cell Biol. 1997, 138, $203-213$. [CrossRef] [PubMed]

44. Kang, J.S.; Mulieri, P.J.; Hu, Y.; Taliana, L.; Krauss, R.S. Boc, an ig superfamily member, associates with cdo to positively regulate myogenic differentiation. EMBO J. 2002, 21, 114-124. [CrossRef] [PubMed]

45. Biggs, L.C.; Mikkola, M.L. Early inductive events in ectodermal appendage morphogenesis. Semin. Cell Dev. Biol. 2014, 25-26, 11-21. [CrossRef] [PubMed]

46. Pispa, J.; Thesleff, I. Mechanisms of ectodermal organogenesis. Dev. Biol. 2003, 262, 195-205. [CrossRef]

47. Cobourne, M.T.; Miletich, I.; Sharpe, P.T. Restriction of sonic hedgehog signalling during early tooth development. Development 2004, 131, 2875-2885. [CrossRef] [PubMed]

48. Chiang, C.; Litingtung, Y.; Lee, E.; Young, K.E.; Corden, J.L.; Westphal, H.; Beachy, P.A. Cyclopia and defective axial patterning in mice lacking sonic hedgehog gene function. Nature 1996, 383, 407-413. [CrossRef] [PubMed]

49. Yamagishi, C.; Yamagishi, H.; Maeda, J.; Tsuchihashi, T.; Ivey, K.; Hu, T.; Srivastava, D. Sonic hedgehog is essential for first pharyngeal arch development. Pediatr. Res. 2006, 59, 349-354. [CrossRef] [PubMed]

50. Dassule, H.R.; McMahon, A.P. Analysis of epithelial-mesenchymal interactions in the initial morphogenesis of the mammalian tooth. Dev. Biol. 1998, 202, 215-227. [CrossRef] [PubMed]

51. Kettunen, P.; Karavanova, I.; Thesleff, I. Responsiveness of developing dental tissues to fibroblast growth factors: Expression of splicing alternatives of fgfr1, -2, -3, and of fgfr4; and stimulation of cell proliferation by fgf-2, $-4,-8$, and -9. Dev. Genet. 1998, 22, 374-385. [CrossRef]

52. Kettunen, P.; Laurikkala, J.; Itaranta, P.; Vainio, S.; Itoh, N.; Thesleff, I. Associations of fgf-3 and fgf-10 with signaling networks regulating tooth morphogenesis. Dev. Dyn. 2000, 219, 322-332. [CrossRef] 
53. Sarkar, L. The Wnt Signalling Pathway in Tooth Development. Ph.D. Thesis, University of London, London, UK, 1999.

54. Ahn, Y.; Sanderson, B.W.; Klein, O.D.; Krumlauf, R. Inhibition of wnt signaling by wise (sostdc1) and negative feedback from shh controls tooth number and patterning. Development 2010, 137, 3221-3231. [CrossRef] [PubMed]

55. Klein, O.D.; Minowada, G.; Peterkova, R.; Kangas, A.; Yu, B.D.; Lesot, H.; Peterka, M.; Jernvall, J.; Martin, G.R. Sprouty genes control diastema tooth development via bidirectional antagonism of epithelial-mesenchymal fgf signaling. Dev. Cell 2006, 11, 181-190. [CrossRef] [PubMed]

56. Pummila, M.; Fliniaux, I.; Jaatinen, R.; James, M.J.; Laurikkala, J.; Schneider, P.; Thesleff, I.; Mikkola, M.L. Ectodysplasin has a dual role in ectodermal organogenesis: Inhibition of bmp activity and induction of shh expression. Development 2007, 134, 117-125. [CrossRef] [PubMed]

57. Murashima-Suginami, A.; Takahashi, K.; Sakata, T.; Tsukamoto, H.; Sugai, M.; Yanagita, M.; Shimizu, A.; Sakurai, T.; Slavkin, H.C.; Bessho, K. Enhanced bmp signaling results in supernumerary tooth formation in usag-1 deficient mouse. Biochem. Biophys. Res. Commun. 2008, 369, 1012-1016. [CrossRef] [PubMed]

58. Nakatomi, M.; Hovorakova, M.; Gritli-Linde, A.; Blair, H.J.; MacArthur, K.; Peterka, M.; Lesot, H.; Peterkova, R.; Ruiz-Perez, V.L.; Goodship, J.A.; et al. Evc regulates a symmetrical response to shh signaling in molar development. J. Dent. Res. 2013, 92, 222-228. [CrossRef] [PubMed]

59. Ruiz-Perez, V.L.; Blair, H.J.; Rodriguez-Andres, M.E.; Blanco, M.J.; Wilson, A.; Liu, Y.N.; Miles, C.; Peters, H.; Goodship, J.A. Evc is a positive mediator of ihh-regulated bone growth that localises at the base of chondrocyte cilia. Development 2007, 134, 2903-2912. [CrossRef] [PubMed]

60. Yang, C.; Chen, W.; Chen, Y.; Jiang, J. Smoothened transduces hedgehog signal by forming a complex with evc/evc2. Cell Res. 2012, 22, 1593-1604. [CrossRef] [PubMed]

61. Sharpe, P.T. Neural crest and tooth morphogenesis. Adv. Dent. Res. 2001, 15, 4-7. [CrossRef] [PubMed]

62. Thesleff, I.; Hurmerinta, K. Tissue interactions in tooth development. Differentiation 1981, 18, 75-88. [CrossRef] [PubMed]

63. Koyama, E.; Yamaai, T.; Iseki, S.; Ohuchi, H.; Nohno, T.; Yoshioka, H.; Hayashi, Y.; Leatherman, J.L.; Golden, E.B.; Noji, S.; et al. Polarizing activity, sonic hedgehog, and tooth development in embryonic and postnatal mouse. Dev. Dyn. 1996, 206, 59-72. [CrossRef]

64. Gritli-Linde, A.; Lewis, P.; McMahon, A.P.; Linde, A. The whereabouts of a morphogen: Direct evidence for short- and graded long-range activity of hedgehog signaling peptides. Dev. Biol. 2001, 236, 364-386. [CrossRef] [PubMed]

65. Kratochwil, K.; Galceran, J.; Tontsch, S.; Roth, W.; Grosschedl, R. Fgf4, a direct target of lef1 and wnt signaling, can rescue the arrest of tooth organogenesis in lef1(-/-) mice. Genes Dev. 2002, 16, 3173-3185. [CrossRef] [PubMed]

66. Liu, F.; Chu, E.Y.; Watt, B.; Zhang, Y.; Gallant, N.M.; Andl, T.; Yang, S.H.; Lu, M.M.; Piccolo, S.; Schmidt-Ullrich, R.; et al. Wnt/beta-catenin signaling directs multiple stages of tooth morphogenesis. Dev. Biol. 2008, 313, 210-224. [CrossRef] [PubMed]

67. Nakatomi, M.; Morita, I.; Eto, K.; Ota, M.S. Sonic hedgehog signaling is important in tooth root development. J. Dent. Res. 2006, 85, 427-431. [CrossRef] [PubMed]

68. Liu, Y.; Feng, J.; Li, J.; Zhao, H.; Ho, T.V.; Chai, Y. An nfic-hedgehog signaling cascade regulates tooth root development. Development 2015, 142, 3374-3382. [CrossRef] [PubMed]

69. Steele-Perkins, G.; Butz, K.G.; Lyons, G.E.; Zeichner-David, M.; Kim, H.J.; Cho, M.I.; Gronostajski, R.M. Essential role for $\mathrm{nfi-c/ctf}$ transcription-replication factor in tooth root development. Mol. Cell. Biol. 2003, 23, 1075-1084. [CrossRef] [PubMed]

70. Lesot, H.; Peterkova, R.; Viriot, L.; Vonesch, J.L.; Tureckova, J.; Peterka, M.; Ruch, J.V. Early stages of tooth morphogenesis in mouse analyzed by 3d reconstructions. Eur. J. Oral Sci. 1998, 106 (Suppl. S1), 64-70. [CrossRef] [PubMed]

71. Peterkova, R.; Hovorakova, M.; Peterka, M.; Lesot, H. Three-dimensional analysis of the early development of the dentition. Aust. Dent. J. 2014, 59 (Suppl. S1), 55-80. [CrossRef] [PubMed]

72. Peterkova, R.; Peterka, M.; Viriot, L.; Lesot, H. Dentition development and budding morphogenesis. J. Craniofac. Genet. Dev. Biol. 2000, 20, 158-172. [PubMed]

73. Peterková, R.; Peterka, M.; Viriot, L.; Lesot, H. Development of the vestigial tooth primordia as part of mouse odontogenesis. Connect. Tissue Res. 2002, 43, 120-128. [CrossRef] [PubMed] 
74. Viriot, L.; Lesot, H.; Vonesch, J.L.; Ruch, J.V.; Peterka, M.; Peterkova, R. The presence of rudimentary odontogenic structures in the mouse embryonic mandible requires reinterpretation of developmental control of first lower molar histomorphogenesis. Int. J. Dev. Biol. 2000, 44, 233-240. [PubMed]

75. Tenzen, T.; Allen, B.L.; Cole, F.; Kang, J.S.; Krauss, R.S.; McMahon, A.P. The cell surface membrane proteins cdo and boc are components and targets of the hedgehog signaling pathway and feedback network in mice. Dev. Cell. 2006, 10, 647-656. [CrossRef] [PubMed]

76. Allen, B.L.; Tenzen, T.; McMahon, A.P. The hedgehog-binding proteins gas1 and cdo cooperate to positively regulate shh signaling during mouse development. Genes Dev. 2007, 21, 1244-1257. [CrossRef] [PubMed]

77. Okada, A.; Charron, F.; Morin, S.; Shin, D.S.; Wong, K.; Fabre, P.J.; Tessier-Lavigne, M.; McConnell, S.K. Boc is a receptor for sonic hedgehog in the guidance of commissural axons. Nature 2006, 444, 369-373. [CrossRef] [PubMed]

78. Seppala, M.; Depew, M.J.; Martinelli, D.C.; Fan, C.M.; Sharpe, P.T.; Cobourne, M.T. Gas1 is a modifier for holoprosencephaly and genetically interacts with sonic hedgehog. J. Clin. Investig. 2007, 117, 1575-1584. [CrossRef] [PubMed]

79. Zhang, W.; Kang, J.S.; Cole, F.; Yi, M.J.; Krauss, R.S. Cdo functions at multiple points in the sonic hedgehog pathway, and cdo-deficient mice accurately model human holoprosencephaly. Dev. Cell 2006, 10, 657-665. [CrossRef] [PubMed]

80. Chuang, P.T.; McMahon, A.P. Vertebrate hedgehog signalling modulated by induction of a hedgehogbinding protein. Nature 1999, 397, 617-621. [CrossRef] [PubMed]

81. Reich, A.; Sapir, A.; Shilo, B. Sprouty is a general inhibitor of receptor tyrosine kinase signaling. Development 1999, 126, 4139-4147. [PubMed]

82. Harada, H.; Kettunen, P.; Jung, H.S.; Mustonen, T.; Wang, Y.A.; Thesleff, I. Localization of putative stem cells in dental epithelium and their association with notch and fgf signaling. J. Cell Biol. 1999, 147, 105-120. [CrossRef] [PubMed]

83. Juuri, E.; Saito, K.; Ahtiainen, L.; Seidel, K.; Tummers, M.; Hochedlinger, K.; Klein, O.D.; Thesleff, I.; Michon, F. Sox2+ stem cells contribute to all epithelial lineages of the tooth via sfrp5+ progenitors. Dev. Cell 2012, 23, 317-328. [CrossRef] [PubMed]

84. Seidel, K.; Ahn, C.P.; Lyons, D.; Nee, A.; Ting, K.; Brownell, I.; Cao, T.; Carano, R.A.; Curran, T.; Schober, M.; et al. Hedgehog signaling regulates the generation of ameloblast progenitors in the continuously growing mouse incisor. Development 2010, 137, 3753-3761. [CrossRef] [PubMed]

85. Rodda, S.J.; McMahon, A.P. Distinct roles for hedgehog and canonical wnt signaling in specification, differentiation and maintenance of osteoblast progenitors. Development 2006, 133, 3231-3244. [CrossRef] [PubMed]

86. Passman, J.N.; Dong, X.R.; Wu, S.P.; Maguire, C.T.; Hogan, K.A.; Bautch, V.L.; Majesky, M.W. A sonic hedgehog signaling domain in the arterial adventitia supports resident sca1+ smooth muscle progenitor cells. Proc. Natl. Acad. Sci. USA 2008, 105, 9349-9354. [CrossRef] [PubMed]

87. Fraser, G.J.; Graham, A.; Smith, M.M. Conserved deployment of genes during odontogenesis across osteichthyans. Proc. Biol. Sci. 2004, 271, 2311-2317. [CrossRef] [PubMed]

88. Fraser, G.J.; Bloomquist, R.F.; Streelman, J.T. A periodic pattern generator for dental diversity. BMC Biol. 2008, 6, 32. [CrossRef] [PubMed]

89. Martin, K.J.; Rasch, L.J.; Cooper, R.L.; Metscher, B.D.; Johanson, Z.; Fraser, G.J. Sox2+ progenitors in sharks link taste development with the evolution of regenerative teeth from denticles. Proc. Natl. Acad. Sci. USA 2016, 113, 14769-14774. [CrossRef] [PubMed]

90. Fraser, G.J.; Bloomquist, R.F.; Streelman, J.T. Common developmental pathways link tooth shape to regeneration. Dev. Biol. 2013, 377, 399-414. [CrossRef] [PubMed]

(C) 2017 by the authors. Licensee MDPI, Basel, Switzerland. This article is an open access article distributed under the terms and conditions of the Creative Commons Attribution (CC BY) license (http:/ / creativecommons.org/licenses/by/4.0/). 